\title{
Goodwill: uma análise dos conceitos utilizados em trabalhos científicos ${ }^{1}$
}

\author{
Goodwill: an Analysis of Concepts used in Scientific Works
}

\author{
Eliseu Martins \\ Professor Emérito da Faculdade de Economia, Administração e Contabilidade da \\ Universidade de São Paulo \\ E-mail: emartins@usp.br
}

\section{Diana Lúcia de Almeida}

Mestranda do Programa de Pós-Graduação em Ciências Contábeis da Faculdade de Economia, Administração e Contabilidade da Universidade de São Paulo

E-mail: dalmeida2003@ hotmail.com

\section{Eric Aversari Martins}

Doutorando do Programa de Pós-Graduação em Ciências Contábeis da Faculdade de Economia, Administração e Contabilidade da Universidade de São Paulo

E-mail: ericmartins@usp.br

\section{Patrícia de Souza Costa}

Professora da Faculdade de Ciências Contábeis da Universidade Federal de Uberlândia e Doutoranda do Programa de Pós-Graduação em Ciências Contábeis da Faculdade de Economia, Administração e Contabilidade da Universidade de São Paulo

E-mail: patricia@facic.ufu.br

Recebido em 09.10.2009 * Aceito em 02.12.2009 * $2^{\mathrm{a}}$ versão aceita em 05.05.2010

\section{RESUMO}

A literatura contábil considera que o goodwill representa a diferença entre o valor da empresa e o seu patrimônio líquido avaliado a valores de mercado. A utilização de um conceito divergente desse, na elaboração de pesquisas teóricas ou empíricas, pode gerar resultados distorcidos, conclusões equivocadas, demonstrações financeiras apresentadas incorretamente, entre outros problemas de ordem teórica e prática. Nesse contexto, o objetivo do presente trabalho é verificar se o conceito de goodwill utilizado no desenvolvimento de pesquisas publicadas nos principais periódicos internacionais e nacionais, bem como na elaboração de dissertações e teses na área da contabilidade, é aquele referendado pela literatura contábil como "correto". Por meio de análise de conteúdo, foram analisados 138 trabalhos científicos nacionais e internacionais, que contêm qualquer um dos seguintes termos no título, resumo ou palavras-chave: goodwill, intangible, intangibles, fundo de comércio, intangível e intangíveis. O total de trabalhos analisados está dividido em 60 trabalhos empíricos e 78 teóricos. Desse total geral de trabalhos, apenas 47 apresentam, explicitamente, o conceito de goodwill, sendo

\footnotetext{
${ }^{1}$ Artigo apresentado no $9^{\circ}$ Congresso USP de Controladoria e Contabilidade, São Paulo-SP, 2009.
} 
24 empíricos e 23 teóricos. A maioria desses trabalhos que apresentam o conceito de goodwill o faz para discutir sobre tratamento contábil e avaliação de empresas. Do total de trabalhos com o conceito de goodwill explícito, 18 apresentam conceito divergente daquele definido pela literatura contábil. Os erros conceituais foram classificados em seis categorias, sendo que $61 \%$ deles se referem ao cálculo do goodwill como sendo a diferença entre o valor de mercado (somente calculado ou efetivamente pago) e o valor contábil do patrimônio.

Palavras-Chave: Goodwill. Fundo de Comércio. Ativos Intangíveis.

\begin{abstract}
The accounting literature considers that goodwill represents the difference between the market value of an entity and the fair value of its identifiable net assets. The use of a divergent concep, in theoretical or empirical researches can result in distorted results, wrong conclusions, incorrect financial statements, among other theoretical and empirical problems. Thus, the objective of this study is to verify if the concept of goodwill used in researches published in the main international and Brazilian journals, as well as in the elaboration of dissertations and theses in the accounting area in Brazil, is that referred by the accounting literature as the "correct". Using contents analysis, 138 national and international works containing one of the following terms in the title, abstract or keywords were analysed: goodwill, intangible, intangibles, fundo de comércio, intangível and intangíveis. The total of works analysed are divided in 60 empirical works and 78 theoretical. From the general total of works, only 47 explicitly present the goodwill's concept, being 24 empirical and 23 theoretical. Most of the works which presents the goodwill concept did it to discuss the accounting treatment and companies'valuation. From the total of works with the goodwill concept explicitly presented, 18 present a divergent concept from that one defined by the accounting literature. The mistakes are divided in 6 categories, being that $61 \%$ of the mistakes founded referes to the calculation of goodwill as the difference between the market value (only calculated or paid) and the book value of the net assets.
\end{abstract}

Keywords: Goodwill. Intangible Assets. Intangibles.

\title{
1 INTRODUÇÃO
}

A disseminação da metodologia positiva aplicada às Ciências Contábeis tem trazido avanços significativos para o estudo dessa ciência social. Testes empíricos vêm sendo realizados com o intuito de se comprovar a validade e/ou a utilidade prática de conceitos e teorias. Os resultados obtidos por meio desses estudos têm apresentado direções singulares para o desenvolvimento da Contabilidade, abrindo caminhos para a pesquisa e o ensino. 
Todavia, para que os resultados obtidos por meio da aplicação de testes empíricos possam ser validados, as definições conceituais que formam a base desse processo precisam ser sólidas e alinhadas com a teoria no seu mais desenvolvido nível (GUJARATI, 2006). Entretanto, é possível encontrar, na literatura científica contábil, diversas aplicações de testes estatísticos com base em conceitos que não representam o entendimento teórico mais reconhecido na academia.

Mas não somente trabalhos com enfoque puramente empírico apresentam distorções derivadas da inadequada utilização de conceitos. Artigos com caráter teórico, também, são encontrados com problemas conceituais, com as mesmas consequências de implicações teóricas e práticas. Não se está aqui tratando de trabalhos voltados para a elaboração de novos conceitos e, sim, dos que utilizam definições divergentes das estabelecidas pela teoria contábil para a realização de seus testes ou discussões teóricas. Conceitos amplamente validados pela literatura contábil vêm sendo aplicados de forma inadequada.

A utilização de conceitos divergentes daqueles estabelecidos não somente pela academia mas também pelas regras contábeis vigentes pode ter sérias implicações teóricas e práticas, tais como: resultados das pesquisas enviesados, informações erroneamente apresentadas, análises divergentes da realidade, decisões incorretas podem ser tomadas. Enfim, diversas consequências indesejáveis podem ocorrer pela aplicação de conceitos incorretos ou inadequados.

Um caso típico, na literatura contábil, é o de Fundo de Comércio ${ }^{2}$ (também chamado de goodwill ou ágio por expectativa de rentabilidade futura). O conceito de goodwill, referendado pela literatura contábil, é o montante de lucros futuros esperados acima da rentabilidade normal de uma empresa, mensurado pela diferença entre o valor da empresa e o seu patrimônio líquido avaliado a valores de mercado. Todavia, conceitos divergentes desse têm sido utilizados.

Diante do exposto, o problema de pesquisa é: o conceito de goodwill utilizado nas pesquisas nacionais e internacionais está em conformidade com a literatura contábil? O objetivo é verificar se tais conceitos aplicados na elaboração dessas pesquisas são alinhados

\footnotetext{
${ }^{2}$ Vale ressaltar que se está tratando, neste trabalho, do conceito contábil de Fundo de Comércio e não do conceito jurídico, uma vez que há diferenças no entendimento desse termo por parte das duas ciências.
} 
àqueles referendados pela literatura contábil, bem como apresentar possíveis efeitos nocivos dos resultados por elas apresentados.

Para a operacionalização do estudo, foram analisados 138 trabalhos científicos nacionais e internacionais. Desse total, 47 apresentam, explicitamente, o conceito de goodwill e 18 deles mostram conceito divergente daquele referendado pela literatura contábil: goodwill é mensurado como sendo a diferença entre o valor total da empresa e seu patrimônio líquido avaliado a valores de mercado. A maioria das imprecisões conceituais encontradas refere-se ao cálculo do goodwill como sendo a diferença entre o valor de mercado (pago ou não) e o valor contábil do patrimônio.

O artigo é composto por seis seções. Após essa introdução é apresentado o referencial teórico sobre o conceito de goodwill. Na terceira seção, trata-se da metodologia da pesquisa. A quarta trata das limitações da pesquisa realizada. Na quinta, abordam-se os resultados da pesquisa. A sexta traz as considerações finais e as recomendações para pesquisas futuras.

\section{REFERENCIAL TEÓRICO}

Segundo Martins (1972, p. 30), "ativo é o futuro resultado econômico que se espera obter de um agente". Note-se a ênfase no resultado gerado pelo agente e não no agente gerador em si. Já para Hendriksen e Van Breda (2007, p. 286), ativo consiste em "potenciais de fluxo de serviço ou direitos a benefícios futuros sob controle de uma organização”. Esses autores acrescentam outra característica relevante: o controle de tais benefícios. Iudícibus (2006, p. 139), por sua vez, menciona que ativo consiste nos "[...] recursos controlados por uma entidade capazes de gerar, mediata ou imediatamente, fluxos de caixa." Esse autor apresenta um entendimento amplo, incluindo os ativos tangíveis e os intangíveis.

Em síntese, a literatura contábil define o ativo como benefícios econômicos (potenciais fluxos de caixa) controlados pela entidade. E tais benefícios podem ser gerados por recursos tangíveis ou intangíveis.

Hendriksen e Van Breda (2007, p. 387) definem ativos intangíveis como:

[...] ativos que carecem de substância. Como tais, esses ativos devem ser reconhecidos sempre que preenchem os requisitos de reconhecimento de todo e qualquer ativo, ou seja, devem atender à definição de um ativo, devem ser mensuráveis e devem ser relevantes e precisos. 
Segundo esses autores, existem diversos itens classificáveis como intangíveis, podendo ser eles identificáveis ou não identificáveis. Um exemplo comum de um ativo intangível não identificável é o goodwill.

Segundo Glautier e Underdown (2001, p. 167),

Goodwill pode ser descrito como a soma daqueles atributos intangíveis de um negócio que contribuem para o seu sucesso, tais como: uma localização favorável, uma boa reputação, a habilidade e perícia dos seus empregados e gestores e sua relação duradoura com credores, fornecedores e clientes. ${ }^{3}$

Tais intangíveis juntos formam o goodwill, que "é o valor presente descontado de lucros futuros superiores esperados (lucros futuros esperados menos os lucros normais do setor) ${ }^{4}$ " (SCHOREDER; CLARK, 1998, p. 432). Por sua vez, o Comitê de Pronunciamentos Contábeis, no seu pronunciamento CPC 15 - Combinação de negócios, assim define goodwill:

é um ativo que representa benefícios econômicos futuros resultantes dos ativos adquiridos em combinação de negócios, os quais não são individualmente identificados e separadamente reconhecidos.

Assim verifica-se que o goodwill é um ativo intangível que surge quando a entidade possui uma capacidade de gerar lucros superiores ao normal para o setor no qual atua por conta da sinergia de diversos ativos intangíveis que não podem ser isoladamente identificados.

Ocorre que o conceito de goodwill pode ser claramente definido, mas sua mensuração é "um tópico controverso na contabilidade por causa da sua natureza vaga e da dificuldade de se chegar a um valor que seja verificável" (GLAUTIER; UNDERDOWN, 2001, p. 167). Ainda, segundo os mesmos autores, por essa razão é que o goodwill somente é contabilizado quando resultante de uma aquisição, na qual a porção adquirida é superior ao valor dos ativos e passivos líquidos avaliados aos seus respectivos valores de mercado.

\footnotetext{
${ }^{3}$ Tradução livre do original "Goodwill may be described as the sumo $f$ thos intangible attributes of a business which contribute to its success, such as favourable location, a good reputation, the ability and skill of its employees and management, and its long-standing relationships with creditors, suppliers and customers".

${ }^{4}$ Tradução livre do original "equal to the discounted present value of expected superior earnings (expected future earnings less normal earnings for the industry".
} 
Nesse sentido, o CPC 15 (2009), que atualmente apresenta a definição legal de goodwill válida no Brasil, no seu parágrafo 32, exige que ele seja reconhecido nas demonstrações da adquirente mediante a diferença entre o valor total pago por um negócio e a diferença entre os ativos e passivos identificáveis avaliados pelo seu valor justo. Por outro lado, o CPC 4 - Ativos Intangíveis (2008), não permite que o goodwill que não tenha sido adquirido, ou seja, aquele gerado internamente mas ainda não parte de uma negociação de compra, seja contabilizado 5 .

Vale destacar que há uma diferença conceitual entre o goodwill existir e ser efetivamente registrado como ativo. Para que ele possa ser reconhecido contabilmente, ele necessita obrigatoriamente ter sido adquirido, deve ter sido efetivamente pago numa transação com genuínos terceiros (SCOTT, 2009, p. 249 e 252).

O goodwill existe a partir do momento em que os ativos de uma entidade, ao funcionarem como um grupo, produzam um retorno acima daquilo que seria considerado normal (goodwill gerado internamente). Mas, como dito anteriormente, nessa situação, ele não é contabilizado. Mas, ressalte-se, não é contabilizado em virtude da dificuldade intrínseca de sua mensuração, não pelo fato de não existir. Quando há a efetiva transação de aquisição de uma entidade, surge a possibilidade de uma avaliação do seu montante de forma objetiva, resultante da diferença entre o valor patrimonial avaliado a preços de mercado da participação adquirida e o valor efetivamente pago por ele. Nesse caso, o goodwill é conhecido tendo sido adquirido e é, segundo o CPC 15, contabilizado.

Todavia, isso não significa dizer que ele somente surge nesse momento. O goodwill, quando é adquirido, existia antes da transação na forma de goodwill gerado internamente na empresa adquirida (por isso foi pago mais do que o valor patrimonial a preços de mercado) e continua existindo após a compra. Porém, quando a transação efetivamente ocorre é que surge a possibilidade de sua mensuração com um grau de objetividade que permita o seu registro contábil. Hendriksen e Van Breda (2007, p. 392) reforçam essa idéia afirmando que o goodwill poderia, em princípio, ser reconhecido a qualquer momento, comparando o valor de mercado de uma empresa ao valor dos seus ativos líquidos a preços de mercado; todavia tal

\footnotetext{
5 "47 - O ágio derivado da expectativa de rentabilidade futura (goodwill) gerado internamente não deve ser reconhecido como ativo."
} 
procedimento não é realizado devido à dificuldade na mensuração desse ativo quando não envolvido em efetiva transação.

Iudícibus (2006, p. 234) define goodwill como "aquele 'algo a mais' pago sobre o valor de mercado do patrimônio líquido das entidades adquiridas a refletir uma expectativa (subjetiva) de lucros futuros em excesso de seus custos de oportunidade." Ainda, de acordo com esse autor:

[...] o verdadeiro goodwill somente surgirá se os ativos e os passivos das entidades adquiridas ou fundidas forem reavaliados por algum tipo de valor de mercado, de entrada ou saída. Caso isso não tenha sido feito, o goodwill é uma mistura de "goodwill puro" e de outras diferenças de avaliação.

Para Martins (2001, p. 124), “o goodwill pode ser considerado como resíduo existente entre a soma dos itens patrimoniais mensurados individualmente e o valor global da empresa". Sendo assim, esse autor conclui que a diferença entre o goodwill e os demais ativos identificáveis e separáveis é que esses podem ser transacionados individualmente, ao passo que a existência do goodwill está vinculada à empresa, não podendo ser vendido separadamente.

Por fim, vale ressaltar que da totalidade dos livros de teoria da contabilidade que discutem o conceito de goodwill analisados pelos autores (tanto entre os citados quanto outros não incluídos nesse referencial teórico, assim como internacionais e nacionais), somente um apresenta um conceito diferente dos demais. Entendem os autores de se tratar, igualmente, de um erro conceitual (tipificado como tipo II conforme item 5.1), dado que, em nenhum momento no texto, é apresentada qualquer discussão acerca dessa diferença conceitual. (RIBEIRO FILHO, 2009, p. 100).

\subsection{Tipos de definições de Goodwill}

Segundo Martins e Theóphilo (2007), as definições são necessárias para que se possa realizar a condução dos conceitos do nível teórico e abstrato para o empírico e observacional. Nesse sentido, Kerlinger (1980, p. 46) apresenta: "Há dois tipos de definição: constitutiva e operacional. Uma definição constitutiva define palavras com outras palavras”, são definições de dicionários.

Entretanto, dependendo "dos propósitos e contextualização da pesquisa, essa definição poderá comprometer a clareza e precisão dos resultados da investigação" (MARTINS; 
THEÓPHILO, 2007, p. 34). Em contraposição, surge a definição operacional, que segundo Kerlinger (1980, p. 46) "atribui significado a um constructo ou variável especificando as atividades ou 'operações' necessárias para medí-lo ou manipulá-lo”. Assim, esses dois tipos de definição são necessários e complementares para o desenvolvimento do pensamento e da pesquisa científica.

Nesse sentido, a definição constitutiva de goodwill utilizada ao longo da presente pesquisa como a que representa, adequadamente, a posição dos principais autores da literatura contábil e dos mais considerados órgãos normatizadores ${ }^{6}$ é: goodwill é um ativo intangível, que surge nas entidades pela sinergia entre todos os ativos, registrados contabilmente ou não, e outros aspectos (como a gestão, a força de vendas, a capacidade de distribuição, localização, fidelidade da clientela etc.), que promovem retornos acima do considerado normal (expectativa de rentabilidade futura acima do normal).

Por sua vez, a definição operacional, referendada pela literatura contábil, a ser utilizada nesta pesquisa é: goodwill é mensurado como a diferença entre o valor total da empresa e seu patrimônio líquido avaliado a valores de mercado (Equação 1):

$$
\mathrm{GO}=\mathrm{VME}-\mathrm{VPLm}
$$

em que:

$\mathrm{GO}=$ goodwill;

$\mathrm{VME}=$ valor de mercado da entidade;

VPLm = valor do patrimônio líquido da entidade avaliado a preços de mercado, ou seja, com todos seus elementos constitutivos, ativos e passivos, já registrados contabilmente ou não, separáveis e viáveis individualmente, devidamente avaliados pelos seus valores individuais de mercado.

Deve-se atentar, nesse momento, para o fato de que o valor do goodwill apurado com base na definição operacional acima, em algumas situações, pode sofrer influências significativas pela qualidade da apuração tanto do VME quanto do VPLm. No primeiro caso,

\footnotetext{
6 Inclusive, entre eles, a Comissão de Valores Mobiliários (CVM), o Instituto dos Auditores Independentes do Brasil (IBRACON) e o Comitê de Pronunciamentos Contábeis (CPC).
} 
dificuldades de mensuração do valor de mercado dos itens avaliados individualmente podem surgir, bem como em problemas relativos à confiabilidade de tais avaliações. Já na apuração do VPLm muitos fatores tais como: prêmios de controle e negociações em ambiente de alto nível concorrencial, entre outros, podem influenciar no seu resultado. Tais dificuldades podem até mesmo culminar em possíveis manipulações da informação contábil por parte dos elaboradores das demonstrações financeiras.

\subsection{Problemas decorrentes da normatização brasileira}

Muito da confusão que ocorre no Brasil para o entendimento do conceito de goodwill advém do Decreto-Lei n. 1.598 que, assim, define o ágio (BRASIL, 1977, art. 20):

$\S 2^{\circ}$ - O lançamento do ágio ou deságio deverá indicar, dentre os seguintes, seu fundamento econômico:

a) valor de mercado de bens do ativo da coligada ou controlada superior ou inferior ao custo registrado na sua contabilidade;

b) valor de rentabilidade da coligada ou controlada, com base em previsão dos resultados nos exercícios futuros;

c) fundo de comércio, intangíveis e outras razões econômicas.

Ocorre que, ao apresentar dessa maneira o ágio, incorreu o legislador em uma impropriedade conceitual: segregou o fundo de comércio, intangíveis e outras razões econômicas do valor da rentabilidade futura. Tal erro conceitual foi, também, seguido pela Comissão de Valores Mobiliários (1978) em sua Instrução 01:

XXI - o ágio ou deságio computado na ocasião da aquisição do investimento deverá ser contabilizado com indicação do fundamento econômico que o determinou:

a) diferença para mais ou para menos entre o valor de mercado de bens do ativo e o valor contábil desses mesmos bens na coligada ou na controlada;

b) diferença para mais ou para menos na expectativa de rentabilidade baseada em projeção do resultado de exercícios, futuros;

c) fundo de comércio, intangíveis ou outras razões econômicas.

Veja-se que o ágio era segregado em três partes. Com isso, a impropriedade foi desmembrar o goodwill em dois subitens. Afinal, o fundo de comércio (goodwill), nada mais é do que a efetiva expectativa de rentabilidade futura acima dos montantes normais esperados. 
Tal incorreção foi ajustada pela CVM (1996), conforme pode ser verificado na Nota Explicativa à Instrução n. 247 emitida em substituição à Instrução 01 (CVM, 1978):

Uma outra modificação introduzida pela nova Instrução é que ela prevê apenas dois tipos de ágio e deságio com fundamento econômico: i) ágio/deságio decorrente da diferença entre o valor de mercado dos bens e respectivo valor contábil; e ii) ágio/deságio em função de expectativa de resultado futuro (art. $14, \S \S 1^{\circ}$ e $2^{\circ}$ ). A existência de ágio por fundo de comércio, intangíveis etc., está diretamente relacionada à expectativa de rentabilidade futura.

Note-se que há a específica menção aos ágios gerados por fundo de comércio e outros intangíveis como sendo relacionados à expectativa de rentabilidade futura, corroborando o entendimento anteriormente exposto sobre fundo de comércio. Já a própria Instrução n. 247 (CVM, 1996), com redação dada pela Instrução n. 285 (CVM, 1998) traz:

Art. 14 - O ágio ou deságio computado na ocasião da aquisição ou subscrição do investimento deverá ser contabilizado com indicação do fundamento econômico que o determinou.

$\S 1^{\circ} \mathrm{O}$ ágio ou deságio decorrente da diferença entre o valor de mercado de parte ou de todos os bens do ativo da coligada e controlada e o respectivo valor contábil [...] $\S 2^{\circ} \mathrm{O}$ ágio ou o deságio decorrente da diferença entre o valor pago na aquisição do investimento e o valor de mercado dos ativos e passivos da coligada ou controlada $[\ldots]$.

Verifica-se, então, que a impropriedade do conceito de ágio apresentada pelo DecretoLei n. 1.598 (BRASIL, 1977) acabou por acarretar algumas confusões no Brasil. Não existem outras razões econômicas para o pagamento de genuíno ágio (goodwill) que não a expectativa de rentabilidade futura. E mesmo com a correção desse conceito por parte da CVM (1996), ainda há, não só em trabalhos acadêmicos, mas também no mercado financeiro, utilização inadequada do conceito de goodwill.

A utilização do ágio para fins tributários foi incentivada no Brasil com a permissão fiscal de dedutibilidade de ágios resultantes de processos de incorporação reversa. Em muitas situações foram elaborados meios de se contabilizarem ágios gerados internamente, dentro de um grupo econômico, com a finalidade de tomar a sua dedutibilidade. Uma discussão mais profunda dos efeitos fiscais desse tipo de operação e seus impactos pode ser visto em Costa Junior e Martins (2004). 


\section{METODOLOGIA}

A pesquisa é exploratória e qualitativa, realizada por meio de pesquisa bibliográfica e análise de conteúdo. A amostra da pesquisa é composta por artigos publicados em periódicos nacionais e internacionais, bem como por teses e dissertações defendidas em programas nacionais de pós-graduação acadêmicos stricto sensu.

\subsection{Amostra de periódicos e programas de pós-graduação acadêmicos stricto sensu}

Foram utilizados critérios específicos para a seleção dos periódicos e dos programas de pós-graduação acadêmicos stricto sensu. Para a seleção dos periódicos com circulação nacional foi utilizada a lista de periódicos classificados por nível de qualidade na área de avaliação ‘Administração, Ciências Contábeis e Turismo’ do sistema Qualis da Coordenação de Aperfeiçoamento de Pessoal de Nível Superior (CAPES, 2008). Esses periódicos possuem focos de interesse diversos, tais como: estudo das ciências sociais, turismo, administração, contabilidade, finanças e economia. Diante desse fato, dos 133 periódicos dessa lista, classificados com qualidade A, B e C, foram selecionados 38, com foco em contabilidade, administração, economia e finanças para compor a amostra desta pesquisa.

Os periódicos com circulação internacional foram selecionados na base de dados do Journal Citation Reports (JCR, 2007). Anualmente, o JCR analisa os padrões de citações dos periódicos indexados no Social Sciences Citation Index e identifica os periódicos internacionais relevantes de duas áreas específicas: Negócios-Gestão e FinançasContabilidade. A amostra de periódicos internacionais é composta pelos oito periódicos constantes da lista do JCR (2007) que possuem o termo 'accounting' em seu título.

Já para a avaliação de teses e dissertações, foi utilizada a relação de cursos recomendados e reconhecidos pela CAPES (2008a). Constam dessa lista dezenove programas de Ciências Contábeis, Controladoria e Contabilidade da área de Administração, Ciências Contábeis e Turismo. A amostra desta pesquisa é composta por quatro desses programas homologados, por serem os que possuem conceito igual ou superior a 4 .

\subsection{Amostra de artigos, teses e dissertações}


Após a seleção dos periódicos e programas de pós-graduação, foram selecionados os trabalhos a serem analisados. O critério utilizado foi a existência de qualquer um dos termos apresentados no Quadro 1 no título, resumo e/ou palavras-chave dos trabalhos.

Quadro 1 - Termos pesquisados na amostra de trabalhos científicos

\begin{tabular}{|c|c|}
\hline Internacionais & Nacionais \\
\hline Goodwill & Goodwill \\
Intangible & Intangível \\
Intangibles & Intangíveis \\
& Fundo de Comércio \\
\hline
\end{tabular}

Inicialmente, foram pesquisados, apenas, os termos goodwill e fundo de comércio. Todavia, ao longo da realização das pesquisas, notou-se a necessidade de expansão dos termos procurados, uma vez que se apresentaram diversas incorreções conceituais relacionando o termo goodwill com ativos intangíveis. Sendo assim, foram incluídos, na pesquisa, os seguintes termos: intangible, intangibles, intangível e intangíveis. Dessa última, resultaram alguns trabalhos que continham os termos pesquisados, mas que não se referiam aos ativos intangíveis (como, por exemplo, efeitos intangíveis ou recursos intangíveis), sendo esses retirados da amostra.

Para os periódicos nacionais, foi utilizado o sistema de busca constante no site de cada um deles. Quando não disponível, o critério adotado foi acessar cada trabalho e verificar se os termos listados no Quadro 1 constavam do título, resumo e/ou palavras-chave.

Já nos periódicos internacionais, foi utilizada a base de dados do Portal da Capes constante do Sistema Integrado de Bibliotecas da Universidade de São Paulo (USP, 2008).

No que tange aos programas de pós-graduação da amostra, foi utilizado o sistema de busca constante nos seus respectivos sites, exceto o programa da USP, caso em que também foi utilizado adicionalmente o sistema Erudito (FEA, 2008).

Quando os trabalhos não estavam disponíveis nas bases de dados on line foi, igualmente, verificado se o artigo, tese ou dissertação impresso estava disponível na Biblioteca da Faculdade de Economia, Administração e Contabilidade (FEA, 2008a) da USP.

Dentro dos trabalhos selecionados, dez não estavam disponíveis (tanto no site das publicações quanto na biblioteca da USP) para análise, sendo uma tese de livre-docência da USP e nove artigos internacionais. Dessa forma, a amostra final é apresentada na Tabela 1. 
Tabela 1 - Quantidade de trabalhos selecionados

\begin{tabular}{l|c|c|cc}
\hline \multirow{2}{*}{ Tipo } & \multirow{2}{*}{$\begin{array}{c}\text { Goodwill e Fundo } \\
\text { de Comércio }\end{array}$} & $\begin{array}{c}\text { Intangível - Intangíveis } \\
\text { Intangible - Intangibles }\end{array}$ & \multicolumn{2}{c}{ Total } \\
\cline { 4 - 5 } & 5 & 31 & 36 & $26 \%$ \\
\hline Artigos Nacionais & 26 & 41 & $\underline{35}$ & $49 \%$ \\
\hline Artigos Internacionais & $\underline{13}$ & $\underline{22}$ & $\underline{\mathbf{1 3 8}}$ & $\mathbf{1 0 0 \%}$ \\
\hline Teses e Dissertações & $\mathbf{4 4}$ & $\mathbf{9 4}$ & $\mathbf{1 0 0 \%}$ \\
\hline Total & $\mathbf{3 2 \%}$ & $\mathbf{6 8 \%}$ & \\
\hline \% & & &
\end{tabular}

A amostra de trabalhos analisados é equilibrada, sendo 51\% composta por artigos e teses e dissertações nacionais e $49 \%$ de artigos internacionais.

Ao serem selecionados os trabalhos não foi utilizada nenhuma data de corte específica, tendo sido as bases de dados verificadas nas suas totalidades. Sendo assim, o Gráfico 1, a seguir, indica a distribuição da totalidade dos trabalhos ao longo do tempo, estando segregados os volumes totais (barras) e os trabalhos que apresentaram o conceito de goodwill utilizado (linha):

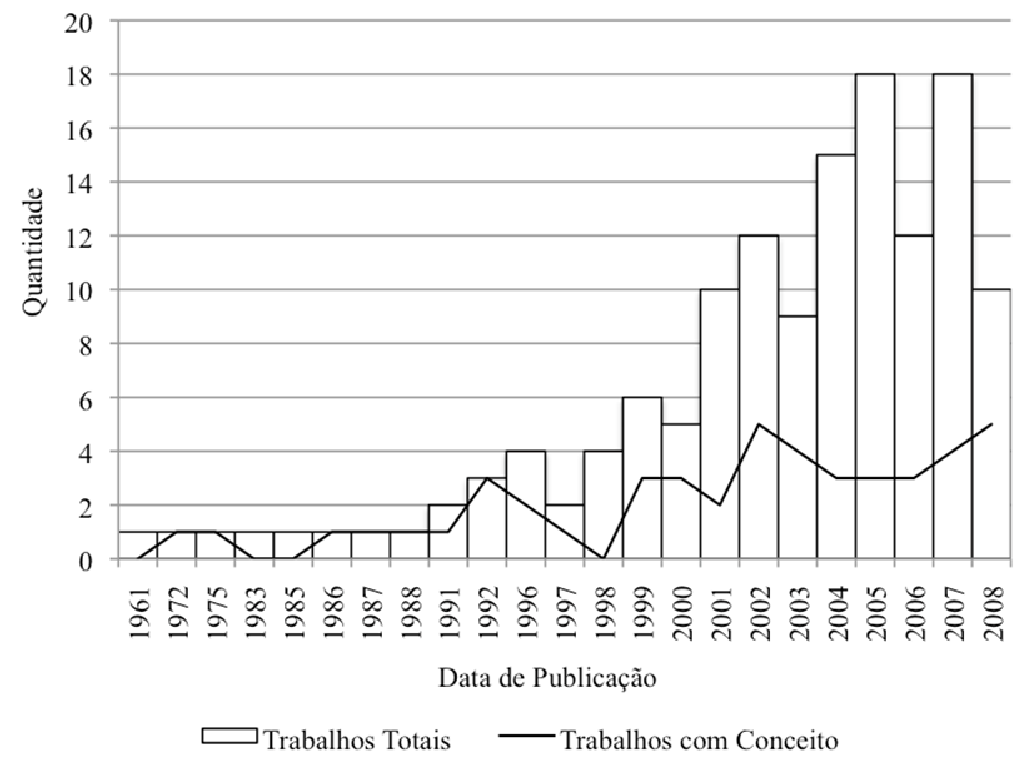

Gráfico 1 - Anos de publicação dos trabalhos selecionados 
Note-se que, até o ano de 1996, não foram encontrados trabalhos publicados em todos os anos. A partir desse período, em todos os anos existiram trabalhos publicados com as características pretendidas, com uma tendência visível de crescimento.

No Gráfico 2 é apresentada uma comparação entre as datas de publicação dos trabalhos que indicam o conceito em análise com as datas dos trabalhos que, contendo o conceito, apresentavam erros.

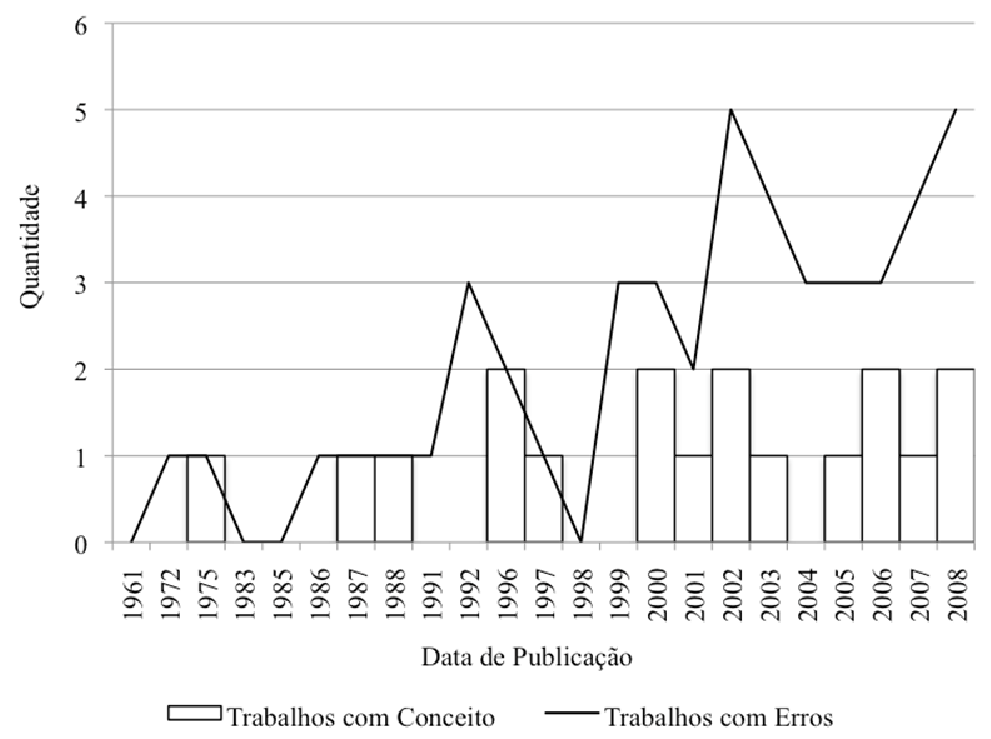

Gráfico 2 - Anos de publicação de trabalhos com conceitos e com erros

\subsection{Análise dos trabalhos}

Os aspectos analisados nos trabalhos apresentados na Tabela 1 foram:

- tipo de estudo: se empírico ou teórico;

- existência do conceito de goodwill: se é explicitamente apresentado ou não;

- adequação teórica: se o conceito utilizado ao longo do trabalho (mesmo não tendo sido explicitamente apresentado) está de acordo com as definições sedimentadas de goodwill constantes da literatura contábil (vide seção 2);

- na existência de erro, qual o tipo de erro e

- aplicação do conceito: em qual contexto é utilizado o conceito de goodwill. 


\section{LIMITAÇÕES DA PESQUISA}

A presente pesquisa não possui um caráter exaustivo no sentido de se analisar a totalidade dos trabalhos científicos que abordam o conceito de goodwill. E até mesmo antes de se ater aos rigores estatísticos para a seleção de amostras e análise de resultados, sua intenção precípua é realizar um levantamento exploratório acerca da existência de erros conceituais.

Uma limitação da amostra é decorrente dos diferentes ou inexistentes sistemas de busca de trabalhos nos sites dos periódicos e dos programas de pós-graduação. Por exemplo, alguns permitem somente a busca no título e resumo, outros somente no texto integral e assim por diante. Dessa maneira, em alguns periódicos e programas de pós-graduação, foi realizada a busca dos termos definidos no quadro 1 no título, resumo e/ou palavras -chave, acessando cada trabalho individualmente.

No que diz respeito à distribuição das datas de publicação ao longo do tempo, não foi realizada nenhuma análise aprofundada sobre o aumento de trabalhos verificados (conforme Gráfico 1).

Ainda, o referencial teórico adotado e apresentado na segunda seção representa o entendimento dos autores do presente trabalho sobre o tema tratado na literatura contábil e nos principais conjuntos de normas contábeis internacionais.

\section{DISCUSSÃO DOS RESULTADOS}

Dos 138 trabalhos analisados, apenas 47 (34\%) apresentam explicitamente o conceito de goodwill (Tabela 2). Apesar desse fato, foi verificada a forma de utilização do conceito, por meio da análise de todos os textos. Também foi analisada a natureza empírica ou teórica de cada um dos trabalhos. Assim, obtiveram-se os resultados apresentados na Tabela 2, independentemente de os conceitos utilizados serem corretos ou não. 
Tabela 2 - Natureza dos trabalhos e existência do conceito

\begin{tabular}{|c|c|c|c|c|c|c|c|c|c|}
\hline \multirow[b]{3}{*}{ Título } & \multicolumn{3}{|c|}{ Trabalhos Empíricos } & \multicolumn{3}{|c|}{ Trabalhos Teóricos } & \multicolumn{3}{|c|}{ Total } \\
\hline & \multirow[t]{2}{*}{ Total } & \multicolumn{2}{|c|}{$\begin{array}{c}\text { Com conceito } \\
\text { definido }\end{array}$} & \multirow[t]{2}{*}{ Total } & \multicolumn{2}{|c|}{$\begin{array}{l}\text { Com conceito } \\
\text { definido }\end{array}$} & \multirow[t]{2}{*}{ Total } & \multicolumn{2}{|c|}{$\begin{array}{c}\text { Com conceito } \\
\text { definido }\end{array}$} \\
\hline & & Quant. & $\%$ & & Quant. & $\%$ & & Quant. & $\%$ \\
\hline Artigos Nacionais & 17 & 2 & $12 \%$ & 19 & 7 & $37 \%$ & 36 & 9 & $25 \%$ \\
\hline Artigos Internacionais & 22 & 10 & $45 \%$ & 45 & 5 & $11 \%$ & 67 & 15 & $22 \%$ \\
\hline Teses e Dissertações & $\underline{21}$ & $\underline{12}$ & $57 \%$ & $\underline{14}$ & $\underline{11}$ & $79 \%$ & $\underline{35}$ & $\underline{23}$ & $\underline{66 \%}$ \\
\hline Total & 60 & 24 & $40 \%$ & 78 & 23 & $29 \%$ & 138 & 47 & $34 \%$ \\
\hline
\end{tabular}

Verifica-se que $66 \%$ dos trabalhos não apresentam o conceito, em destaque, os internacionais (78\%). Nesse aspecto, entende-se que, por se tratar de um termo há tempos amplamente utilizado no exterior (Monobe, 1986, cita que o seu primeiro uso ocorreu em 1571, no Norte da Inglaterra), os artigos assumam o pressuposto de que o conceito já está sedimentado, não requerendo ser explorado. Ainda, muitos deles tratam de trabalhos relacionados com o tratamento dado ao goodwill por normas contábeis (como, por exemplo, o FASB), de forma que o conceito não é explicitado, ficando evidente que deve estar sendo utilizado aquele constante da norma em estudo.

As principais aplicações dos 47 trabalhos que explicitam o conceito de goodwill estão detalhadas na Tabela 3.

Tabela 3 - Aplicação dos conceitos

\begin{tabular}{l|c|c|c|c|c|c|c}
\hline \multicolumn{1}{c|}{ Publicação } & $\begin{array}{c}\text { Avaliação } \\
\text { Ativo } \\
\text { Intangível }\end{array}$ & $\begin{array}{c}\text { Tratamento } \\
\text { Contábil }\end{array}$ & $\begin{array}{c}\text { Manipulação } \\
\text { Contábil }\end{array}$ & $\begin{array}{c}\text { Avaliação } \\
\text { de } \\
\text { Empresas }\end{array}$ & $\begin{array}{c}\text { Capital } \\
\text { Intelectual }\end{array}$ & Outros & Total \\
\hline Artigos Nacionais & 3 & - & - & - & 3 & 3 & 9 \\
\hline Artigos Internacionais & - & 9 & 4 & 1 & 1 & - & 15 \\
\hline Teses e Dissertações & $\underline{4}$ & $\underline{3}$ & $\underline{1}$ & $\underline{8}$ & $\underline{5}$ & $\underline{23}$ \\
\hline Total & $\mathbf{7}$ & $\mathbf{1 2}$ & $\mathbf{5}$ & $\mathbf{9}$ & $\mathbf{6}$ & $\mathbf{8}$ & $\mathbf{4 7}$ \\
\hline
\end{tabular}

Todavia, o aspecto mais importante analisado, nesse estudo, refere-se à adequação do conceito ante a literatura contábil. Assim, têm-se os resultados apresentados na Tabela 4.

Tabela 4 - Quantidade de Erros

\begin{tabular}{c|c|c|c}
\hline Título & Trabalhos Empíricos & Trabalhos Teóricos & Total \\
\hline
\end{tabular}




\begin{tabular}{|c|c|c|c|c|c|c|c|c|c|}
\hline & \multirow[t]{2}{*}{ Total } & \multicolumn{2}{|c|}{$\begin{array}{l}\text { Conceito } \\
\text { Incorreto }\end{array}$} & \multirow[t]{2}{*}{ Total } & \multicolumn{2}{|c|}{$\begin{array}{l}\text { Conceito } \\
\text { Incorreto }\end{array}$} & \multirow[t]{2}{*}{ Total } & \multicolumn{2}{|c|}{$\begin{array}{l}\text { Conceito } \\
\text { Incorreto }\end{array}$} \\
\hline & & Quant. & $\%$ & & Quant. & $\%$ & & Quant. & $\%$ \\
\hline Artigos Nacionais & 2 & 0 & $0 \%$ & 7 & $\overline{5}$ & $71 \%$ & 9 & $\overline{5}$ & $56 \%$ \\
\hline Artigos Internacionais & 10 & 6 & $60 \%$ & 5 & 1 & $20 \%$ & 15 & 7 & $47 \%$ \\
\hline Teses e Dissertações & $\underline{12}$ & $\underline{4}$ & $33 \%$ & $\underline{11}$ & $\underline{2}$ & $18 \%$ & $\underline{23}$ & $\underline{6}$ & $26 \%$ \\
\hline Total & 24 & 10 & $42 \%$ & 23 & 8 & $35 \%$ & 47 & 18 & $38 \%$ \\
\hline
\end{tabular}

Os resultados constantes da Tabela 4 somente consideram os artigos que apresentam a conceituação de goodwill. Com isso, tem-se, proporcionalmente, que os trabalhos empíricos amostram uma média de $42 \%$ baseados em conceitos de goodwill divergentes dos amplamente aceitos, enquanto os trabalhos de natureza teórica apresentam 35\%.

\subsection{Tipos de erros encontrados}

Os erros conceituais encontrados foram classificados em seis categorias de acordo com a sua natureza (Quadro 2).

Quadro 2 - Classificação dos tipos de erros encontrados

\begin{tabular}{|c|l|}
\hline \multicolumn{2}{|c|}{ Tipos de Divergência } \\
\hline I & Diferença entre o PL a valor contábil e PL a valores de mercado \\
\hline II & Diferença entre PL a valor contábil e o valor pago \\
\hline III & Diferença entre valor pago e valor da empresa \\
\hline IV & Diferença entre PL a valor contábil e o valor da empresa \\
\hline V & Excesso do valor pago (omissão quanto a que se refere) \\
\hline VI & Diferença entre o PL ao custo de reposição e o valor pago \\
\hline
\end{tabular}

Apresenta-se na Tabela 5 a quantidade de erros distribuídos nas seis tipologias definidas no Quadro 2.

Tabela 5 - Total de erros por tipologia

\begin{tabular}{c|c|c|c|c|c|c|c|c|c|c}
\hline \multirow{2}{*}{ Publicação } & \multirow{2}{*}{ I } & II & \multirow{2}{*}{ III } & \multirow{2}{*}{ IV } & \multirow{2}{*}{ V } & \multirow{2}{*}{ VI } & \multicolumn{2}{|c}{ Total com Erro } & \multicolumn{2}{|c}{ Total com Conceito } \\
\cline { 5 - 8 } & & & & & & & $(1)$ & $\%$ & Quant. & $\%$ \\
\hline
\end{tabular}




\begin{tabular}{c|c|c|c|c|c|c|c|c|c|c}
\hline Artigos Nacionais & 1 & 1 & - & 3 & - & - & $\mathbf{5}$ & $28 \%$ & $\mathbf{9}$ & $56 \%$ \\
\hline Artigos Internacionais & 1 & 2 & - & - & 3 & 1 & $\mathbf{7}$ & $39 \%$ & $\mathbf{1 5}$ & $47 \%$ \\
\hline Teses e Dissertações & - & $\underline{2}$ & $\underline{1}$ & $\underline{3}$ & - & - & $\underline{\mathbf{6}}$ & $33 \%$ & $\underline{\mathbf{2 3}}$ & $26 \%$ \\
\hline \multicolumn{1}{c|}{ Total } & $\mathbf{2}$ & $\mathbf{5}$ & $\mathbf{1}$ & $\mathbf{6}$ & $\mathbf{3}$ & $\mathbf{1}$ & $\mathbf{1 8}$ & $100 \%$ & $\mathbf{4 7}$ & $38 \%$ \\
\hline $\boldsymbol{\%}$ & $11 \%$ & $28 \%$ & $6 \%$ & $33 \%$ & $17 \%$ & $6 \%$ & $100 \%$ & & & \\
\hline
\end{tabular}

Note-se que o erro mais comum é o de tipo IV (33\%), seguido do erro tipo $\mathrm{II}^{7}(28 \%)$. Dessa forma, $61 \%$ dos erros estão relacionados ao cálculo do goodwill como sendo a diferença entre o valor de mercado (pago ou não) e o valor contábil do patrimônio. A figura 1 representa os tipos de erros e o esquema da definição operacional de goodwill (G).

O erro tipo I representa o goodwill como a diferença entre o patrimônio líquido (PL) da entidade avaliado a valor contábil e o avaliado a valores de mercado (Figura 1). É importante ressaltar que PL a valor de mercado é aquele que representa o valor dos ativos e passivos pelos quais os itens patrimoniais poderiam ser individualmente vendidos (valores de saída). O PL a valores de mercado difere do valor econômico da empresa, que é o valor pelo qual ela é (ou pode ser) transacionada.

Essa diferença é comumente confundida com o goodwill, pois ambos recebem o nome de ágio na normatização contábil brasileira (ver na seção 2 discussão sobre a IN CVM n. 247). Entretanto, há dois tipos de ágio: o representado aqui pelo erro tipo I e o goodwill. Ocorre que a diferença entre o patrimônio contábil e o patrimônio a valores de mercado não existe por conta de expectativa de rentabilidade futura. Ela acontece por diversos fatores, afetando principalmente o valor dos ativos permanentes, mas também dos passivos, tais como: defasagens devido à inexistência de correção monetária, erros de previsão da depreciação, novas tecnologias referentes aos equipamentos de produção, diferenças significativas entre as taxas de juros de mercado e as taxas pactuadas dos passivos existentes. O relevante é atentar para o fato de que nenhuma dessas circunstâncias representa qualquer tipo de mais-valia da empresa por conta de lucros futuros acima dos normais esperados e, sim, defasagens em relação a dois diferentes critérios de avaliação patrimonial: o critério contábil (fortemente calcado no custo como base de valor) e o critério de avaliação a preços de mercado (valores de saída).

\footnotetext{
${ }^{7}$ Ressalte-se que a expressão "erro tipo I" ou "erro tipo II", utilizadas no presente artigo não devem ser confundidas com os conceitos estatísticos de erro tipo I e erro tipo II.
} 


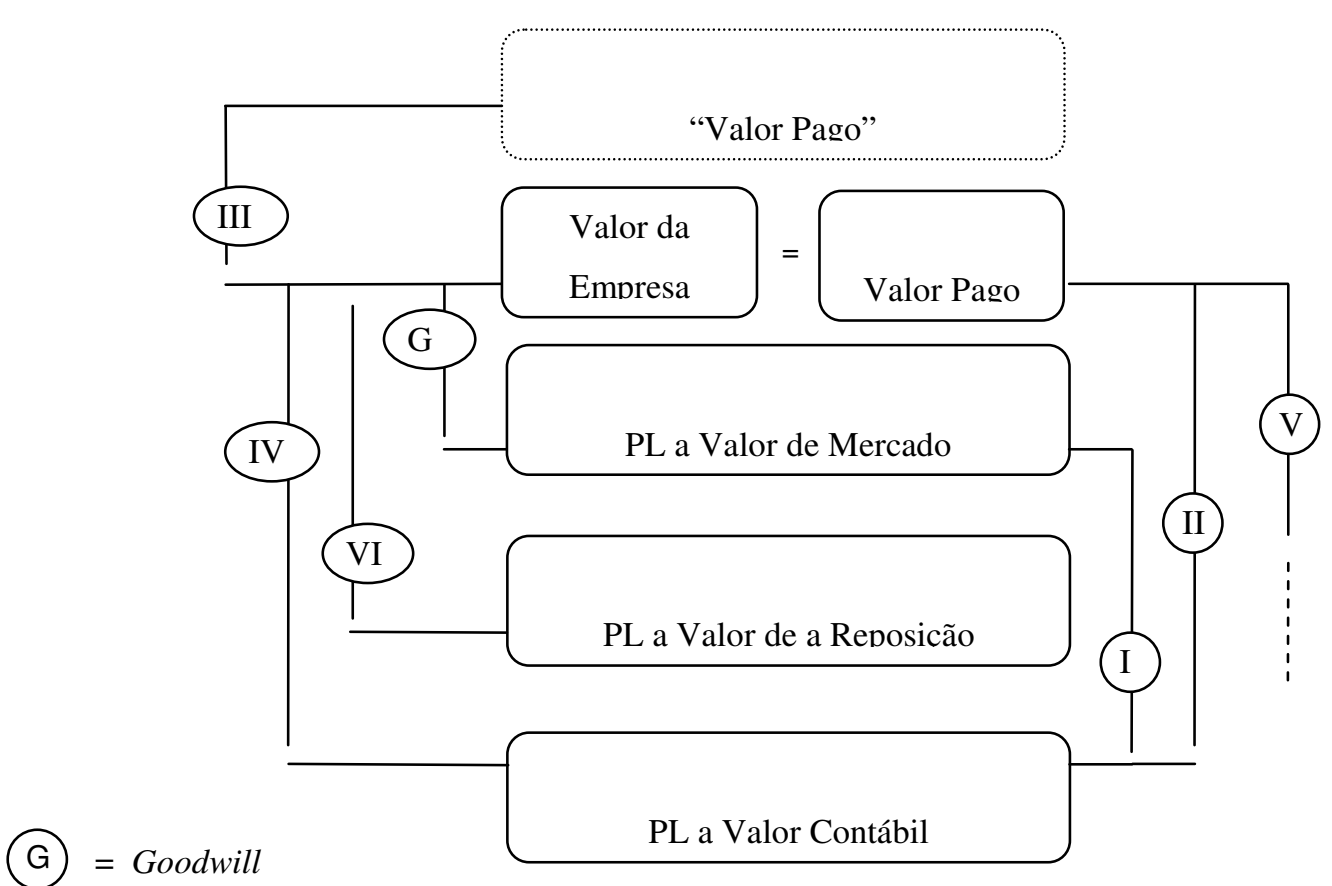

Figura 1 - Esquema dos tipos de erro encontrados e do Goodwill

O erro tipo II refere-se à diferença entre o patrimônio a valores contábeis (o mesmo no caso do erro tipo I) e o valor efetivamente pago pela entidade (Figura 1). Note-se que, nessa figura, o valor da empresa é igual ao valor pago pela empresa, ou seja, a entidade possui um valor pelo qual ela pode ser normalmente transacionada (o seu valor econômico) que se materializa quando ocorre uma real transação. Assim, o valor pago pela entidade representa o efetivo valor da empresa, não havendo diferença entre ambos os montantes. Ora, esse tipo de erro incorpora o erro tipo I, ao considerar que o goodwill abrange a diferença entre o valor contábil e o valor a preços de mercado, o que já foi demonstrado ser incorreto. Assim, a diferença entre o valor contábil e o valor pago pela entidade contém, dentro dela, o goodwill, mas não representa, exclusivamente, esse valor, uma vez que também abrange as diferenças entre os valores contábeis e os valores de saída dos respectivos itens patrimoniais.

O erro tipo III pode ser considerado como derivado do problema da definição incorreta de ágio apresentada pelo Decreto-Lei n. 1.598 (ver seção 2). Na figura 1, verifica-se que há duas caixas com o valor pago. A primeira, com a linha pontilhada e entre aspas, representa um valor pago pela entidade diferente do valor de mercado. Essa primeira caixa deriva de um conceito incorreto, de que existe a possibilidade de ocorrer um pagamento maior do que o 
valor efetivo de mercado da entidade. Esse incorreto entendimento decorre daquele Decreto que considera fundo de comércio, intangíveis e outras razões econômicas, como um item separado da expectativa de rentabilidade futura, porém, o goodwill deriva dessa rentabilidade futura e está nela representado. Assim, não há como se pagar um valor superior ao representado pelo valor efetivo de mercado da empresa. Estar-se-ia, nesse caso, jogando dinheiro fora, uma vez que não há nenhuma razão para o pagamento desse valor a mais. Já a segunda caixa com o valor pago sem aspas, está na mesma linha do valor de mercado da empresa e a ele é considerado igual, ou seja, paga-se pela empresa o valor que ela efetivamente vale no mercado, não mais que isso.

Na Figura 1 se pode notar a semelhança entre os erros tipo IV e II, bastando verificar que o valor de mercado é igual ao valor pago pela entidade. A única diferença entre eles é que, nesse caso, se está apurando o goodwill não com base no valor efetivamente pago, mas no valor de mercado avaliado da entidade, sem que haja uma transação ocorrida. Note-se que o erro jaz na comparação com o valor contábil patrimonial: o ágio, apurado dessa forma, englobaria, também, a diferença de avaliação entre o valor contábil e o valor de mercado dos itens patrimoniais, que como já apresentado na discussão do erro tipo II, não é parte do goodwill.

O erro tipo V ocorre por indefinição do que se está comparando com o valor pago. De acordo com os trabalhos analisados, deve-se utilizar o valor pago pela entidade, mas não é mencionado o valor que deve ser comparado com ele para a apuração do goodwill. Tal erro aponta para o sempre necessário cuidado na definição (seja ela operacional ou constitutiva) dos conceitos utilizados. Definir de forma imprecisa, vaga, com elementos faltantes, é o mesmo que definir de maneira incorreta.

O erro tipo VI representa a diferença entre o valor pago e o PL a custo de reposição. Segundo Martins (1972), o excesso entre o valor pago e o patrimônio líquido a custo de reposição é uma boa aproximação do que é o goodwill, mas não o representa de forma fiel. E essa pode ser uma verdade em algumas situações, não necessariamente em todas. Como já dito na discussão do erro tipo I, o patrimônio deve ser avaliado a preços de saída para que se obtenha o goodwill. A utilização de preços de entrada (custos de reposição dos ativos) nada mais é do que uma aproximação que pode ser utilizada em casos que não se tenha a informação dos valores de saída. Mas sempre com essa limitação do seu uso e com a indicação de tal limitação no trabalho que se está realizando. Um exemplo típico desse tipo de 
erro ocorre com trabalhos que apuram o goodwill considerando o patrimônio líquido calculado com base em ativos reavaliados. A reavaliação representa a avaliação dos itens permanentes pelo seu custo de reposição, pelo valor que se gastaria para adquirir os mesmo ativos no mercado (valores de entrada). E tais montantes podem, mas não obrigatoriamente, se aproximar daqueles pelos quais a entidade conseguiria vender esses ativos (valores de saída). Assim, quando da utilização dos valores reavaliados como proxy dos de saída, sempre deve haver a explícita menção ao fato de que essa é uma aproximação utilizada no cálculo do goodwill.

\section{CONSIDERAÇÕES FINAIS E RECOMENDAÇÕES PARA PESQUISAS FUTURAS}

O presente trabalho, com a intenção de verificar a existência de erros na definição conceitual de goodwill, analisou artigos científicos publicados em periódicos nacionais e internacionais, bem como teses e dissertações de programas brasileiros de pós-graduação acadêmicos stricto sensu em Contabilidade.

Foram analisados 138 artigos. Desse total, 47 apresentam a definição conceitual de goodwill e dezoito estão incorretas. Os erros foram segregados em seis diferentes tipos e $61 \%$ desses se referem ao cálculo do goodwill como a diferença entre o valor de mercado (pago ou não) e o valor contábil do patrimônio.

Os erros conceituais, na apuração do goodwill, podem resultar em conclusões incorretas, invalidação dos resultados, deformações nas informações apresentadas nas demonstrações contábeis, entre outros problemas de ordem teórica e prática. E, certamente, o leitor mais atento desqualificará os resultados dos trabalhos se forem obtidos com base em premissas incorretas.

Um trabalho, por exemplo, que busca identificar uma relação entre os preços de mercado das ações de uma companhia e a existência de goodwill. As conclusões, com base no goodwill conceituado como a diferença entre o preço de mercado e o patrimônio a valores contábeis, podem estar condicionadas a erros. O grau de divergência entre o goodwill apurado com base nesse conceito e o goodwill real pode variar dependendo do setor de atuação da entidade, de sua estrutura de capital, da idade média dos seus ativos permanentes, da falta de correção monetária, do registro de depreciação com base em critérios fiscais. 
A utilização de conceitos não referendados na literatura contábil e os seus efeitos nocivos nos trabalhos acadêmicos podem provocar um retardo no desenvolvimento científico, uma vez que esforço é aplicado na realização de textos que não possuem potencial de inovação e contribuição para o crescimento do conhecimento.

Mais ainda, a existência de tais erros conceituais representa, ainda, o reflexo da qualidade da pesquisa que está sendo realizada no momento, indicando falhas não somente de formação dos pesquisadores, bem como dos editores das revistas e revisores dos trabalhos a serem publicados. Dessa forma, não estão sendo aplicados filtros adequados nas revisões dos trabalhos aprovados para publicação nacional e internacional (restrito à amostra analisada).

A pesquisa contábil, no Brasil, passa por um processo de crescimento da utilização de rigorosos métodos científicos calcados em análises estatísticas. Esses procedimentos metodológicos estão permitindo um grau de confiabilidade nos resultados maior do que os anteriormente obtidos, por exemplo, por meio de estudos de caso. Entretanto, há que se ressaltar que os rigores da metodologia científica não devem somente se ater a tais processos quantitativos, mas devem, também, ser aplicados nos aspectos teórico e conceitual. Somente assim, a pesquisa contábil se desenvolverá com mais solidez.

Mas não somente no campo acadêmico pode haver problemas. Imagine-se o caso de uma entidade que adquire outra com pagamento pelo goodwill. Ora, se o ágio for apurado incorretamente, como se o goodwill fosse, por exemplo, a diferença entre o valor contábil e o valor pago pela empresa, haverá um aumento no montante do ágio em detrimento do valor do ativo. Consequentemente, uma diminuição indevida no valor das futuras depreciações e um aumento incorreto dos lucros apurados pode ocorrer. Adicionalmente, futuros testes de recuperabilidade do goodwill contabilizado como ativo serão realizados com base em um montante incorreto, o que pode provocar perdas por impairment que, na realidade, derivam da comparação de valores incorretos. Ainda, eventuais análises desse balanço estarão, igualmente, comprometidas com a possível apuração de indicadores baseados em valores imprecisos.

Dessa forma, a utilização de conceitos incorretos pode, realmente, afetar não somente a pesquisa acadêmica, mas também ter implicações práticas que podem levar a erros na realização de investimentos e análises financeiras.

Por meio da leitura dos textos selecionados para a realização da presente pesquisa, identificaram-se, além do goodwill, outros termos contábeis conceituados incorretamente, tais 
como: ativo intangível, capital intelectual, ativo diferido. Assim sendo, recomenda-se, para pesquisas futuras, a realização de uma pesquisa com o mesmo perfil desta, mas com a análise crítica do conceito desses conceitos e as suas diferentes utilizações.

\section{Referências}

BRASIL. Decreto-Lei $n$. 1.598, de 26 de dezembro de 1977. Disponível em: <http://www.planalto.gov.br/ccivil/Decreto-Lei/Del1598.htm>. Acesso em: 20 out. 2008.

BRASIL. Lei $n$. 11.638, de 28 de dezembro de 2007. Disponível em:

<http://www.planalto.gov.br/ccivil_03/_ato2007-2010/2007/Lei/L11638.htm>. Acesso em: 20 out. 2008.

CAPES. Coordenação de Aperfeiçoamento de Pessoal de Nível Superior. Qualis. Disponível em: <http://qualis.capes.gov.br/webqualis/ConsultaPeriodicos.faces>. Acesso em: 06 nov. 2008 .

Coordenação de Aperfeiçoamento de Pessoal de Nível Superior. Cursos recomendados e reconhecidos. Disponível em:

$<$ http://conteudoweb.capes.gov.br/conteudoweb/ProjetoRelacaoCursosServlet?acao=pesquisa rIes $\&$ codigoArea $=60200006 \&$ descricaoArea $=$ CI\%CANCIAS+SOCIAIS + APLICADAS+\&de scricaoAreaConhecimento $=$ ADMINISTRA $\% \mathrm{C} 7 \% \mathrm{C} 3 \mathrm{O} \&$ descricaoAreaAvaliacao $=\mathrm{ADMINIS}$ TRA $\% \mathrm{C} 7 \% \mathrm{C} 3 \mathrm{O} \% 2 \mathrm{C}+\mathrm{CI} \% \mathrm{CANCIAS+CONT} \% \mathrm{C} 1 \mathrm{BEIS}+\mathrm{E}+\mathrm{TURISMO}>$. Acesso em: 06 nov. 2008a.

COSTA JUNIOR, J. V.; MARTINS, E. A incorporação reversa com ágio gerado internamente: consequências da elisão fiscal sobre a contabilidade. In: CONGRESSO USP CONTROLADORIA E CONTABILIDADE, 4., 2004, São Paulo. Disponível em: $<$ http://www.congressousp.fipecafi.org/artigos42004/an_resumo.asp?pagina=2>. Acesso em: 23 jun. 2010.

CPC. Comitê de Pronunciamentos Contábeis. CPC 04 - Ativos intangíveis, de 03/10/2008. Disponível em: <http://www.cpc.org.br/pdf/CPC_04.pdf>. Acesso em: 23 jun. 2010.

CPC 15 - Combinação de negócios, de 26/06/2009. Disponível em: < http://www.cpc.org.br/pdf/CPC\%2015.pdf>. Acesso em: 23 jun. 2010.

CVM. Comissão de Valores Mobiliários. Instrução n. 01, de 27 de abril de 1978. Disponível em: <http://www.cvm.gov.br/>. Acesso em: 20 out. 2008.

Instrução n. 247, de 27 de março de 1996. Disponível em:

<http://www.cvm.gov.br/>. Acesso em: 20 out. 2008. 
Nota explicativa à instrução n. 247, de 27 de março de 1996. Disponível em:

$<$ http://www.cvm.gov.br/asp/cvmwww/atos/exiato.asp?Tipo=N\&File=/nota/nota247.htm $>$. Acesso em: 20 out. 2008.

FEA. Faculdade de Economia, Administração e Contabilidade. Biblioteca. Sistema Dedalus. Disponível em: <http://dedalus.usp.br:4500/ALEPH/por/USP/USP/DEDALUS/START>. Acesso em: 6 out. 2008.

Sistema Erudito. Disponível em:

$<$ http://www.fea.usp.br/portalfea/Default.aspx?pagina=TRABALHOSPOS $>$. Acesso em: 6 out. 2008a.

GLAUTIER, M. W. E.; UNDERDOWN, B. Accounting theory and practice. 7., Essex: Prentice Hall, 2001.

GUJARATI, D. N. Econometria básica. 4., Rio de Janeiro: Campus, 2006.

HENDRIKSEN, E. S; VAN BREDA, M. Teoria da contabilidade. 6., São Paulo: Atlas, 2007.

IUDÍCIBUS, S. Teoria da contabilidade. 8., São Paulo: Atlas, 2006.

JCR. Journal Citation Reports. Editions for sciences and social sciences. 2007. Disponível em: <http://admin-apps.isiknowledge.com/JCR/JCR?RQ=LIST_SUMMARY_JOURNAL>. Acesso em: 20 nov. 2008.

KERLINGER, F. Metodologia da pesquisa em ciências sociais. São Paulo: E.P.U /EDUSP., 1980.

MARTINS, E. (Org.). Avaliação de empresas: da mensuração contábil à econômica. São Paulo: Atlas, 2001.

Contribuição à avaliação do ativo intangível. 1972. 109 f. Tese (Doutorado em Controladoria e Contabilidade) - Faculdade de Economia, Administração e Contabilidade, Universidade de São Paulo, São Paulo, 1972.

MARTINS, G. A.; THEÓPHILO, C. R. Metodologia da investigação científica para ciências sociais aplicadas. São Paulo: Atlas, 2007.

MONOBE, M. Contribuição à mensuração e contabilização do goodwill não adquirido. 1986. 183 f. Tese (Doutorado em Controladoria e Contabilidade) - Faculdade de Economia, Administração e Contabilidade, Universidade de São Paulo, São Paulo, 1986.

RIBEIRO FILHO, J. F. et al. (Org.). Estudando teoria da contabilidade. São Paulo: Atlas, 2009.

SCHOROEDER, R. G.; CLARK, M. W. Accounting theory: text and readings. 6., Nova Iorque: Wiley, 1998. 
SCOTT, W. R. Financial accounting theory. 5., Toronto: Pearson Prentice Hall, 2009. USP. Universidade de São Paulo. Sistema Integrado de Bibliotecas (SIBINET). Portal da CAPES. Disponível em: <http://www.usp.br/sibi/>. Acesso em: 6 nov. 2008. 